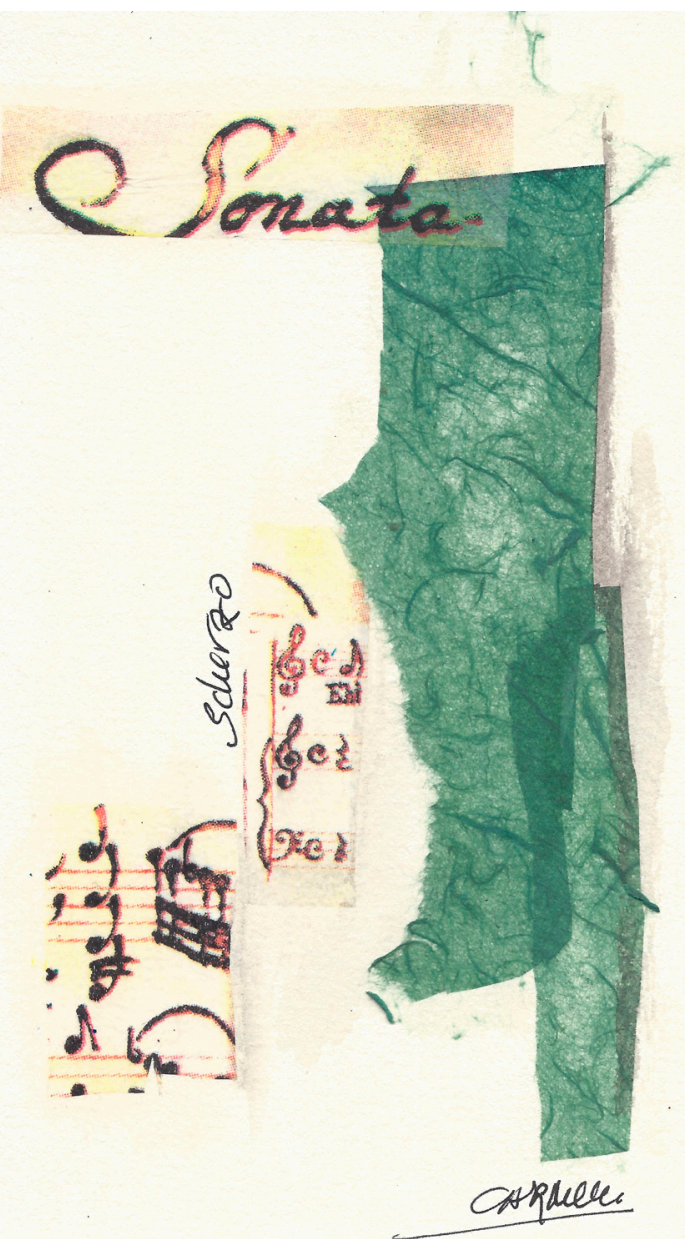


AUTOR: Carmen Franco 


\title{
Harry Potter e a Pedra Filosofal: alguns (re)encontros visuais
}

\author{
Sara Reis da Silva \\ [Recibido, 2 setembro 2019; aceptado, 13 novembro 2019] \\ http://dx.doi.org/10.15304/bgl.55.6046
}

RESUMO Centrado na primeira narrativa da série Harry Potter, de J. K. Rowling, Harry Potter e a Pedra Filosofal (1997), o presente estudo pretende dar conta do dinamismo e da heterogeneidade inerentes à literatura de potencial recepção infanto-juvenil, traço decorrente, em larga medida, do cruzamento interartístico que a este subsistema se encontra subjacente. Do fenómeno editorial destacaremos sucintamente as principais singularidades ideotemáticas e técnico-expressivas, para, de seguida, analisarmos a sua cuidada reedição, datada de 2015. Trata-se de uma obra publicada com uma dimensão/formato considerável, com mais de cem ilustrações, da autoria do inglês Jim Kay. Pretende-se, assim, enfatizar a plasticidade discursiva, bem como a originalidade do seu enredo, repleto de sombras, de claros-escuros, de mistérios ou de enigmas, que possibilitam leituras múltiplas e que deram azo às reinvenções/releituras visuais do artista mencionado. A este exemplar juntamos, ainda, uma edição pop-up, obra da qual apresentaremos uma breve leitura.

PALABRAS-CHAVE: Literatura para a infância e a juventude; Harry Potter e a Pedra Filosofal; ilustração; reedição; teoria dos polissistemas.

ABSTRACT Focusing on the first narrative of the Harry Potter series by JK Rowling, Harry Potter and the Philosopher's Stone (1997), this study intends to account for the dynamism and heterogeneity inherent to children's and youth literature, trait which results, to a large extent, from the artistic intersection that underlies this subsystem. About this editorial phenomenon, we will briefly highlight the main ideothematic and technical-expressive singularities, and then analyze its careful reprint, dated 2015. It is a book published with a considerable size/format, with over a hundred illustrations, by the english artist Jim Kay. Our aim is to emphasize the discursive plasticity, as well as the originality of its plot, full of shadows, lightdark, mysteries or enigmas, that allow for multiple readings and that gave rise to the reinventions/visual re-readings of the mentioned illustrator. To this book we also add a pop-up edition, of which we will present a brief reading, also revealing the potential artistic versatility underlying the Potterian narrative.

KEYWORDS: Children's and youth literature; Harry Potter and the Philosopher's Stone; illustration; re-edition; polysystem theory. 


\section{Introdução}

Tratando-se de uma manifestação de cultura que constitui um subsistema no âmbito dos polissistemas (Even-Zohar, 1997), a literatura para a infância e a juventude possui um carácter dinâmico, complexo e heterogéneo, e emerge, na actualidade e cada vez mais, no cruzamento de diferentes artes e/ou media (Nikolajeva, 2005), designadamente da televisão, do cinema, do teatro, da música, da pintura, da escultura, dos jogos de computador, entre outros. Entende-se, pois e à partida, como uma "twofold comunication" (Ewers, 2009: 31) ou uma "manifestação sintética" (Nikolajeva, 2005: 223), intrinsecamente decorrente da interacção entre diferentes meios de comunicação. Signos convencionais ou palavras apresentam-se ao lado, articulados sinergicamente ou apenas possuindo uma função decorativa ou de embelezamento, de signos icónicos ou ilustrações, compondo, na verdade, dois tipos paralelos/simultâneos de comunicação, o verbal e o visual. Assim sendo, o estudo da literatura para a infância e a juventude não pode ignorar ou negligenciar o aspecto visual das obras (Nikolajeva e Scott, 2011), sob pena de, descurando-se essa gramática fundamental para a leitura e para o entendimento da imagem, já devidamente estipulada, por exemplo, por Nodelman (1988), se percorrer um caminho interpretativo limitado ou incompleto.

Com efeito e em última instância, trata-se de contemplar as relações interartísticas hipo ou hipertextuais, em concreto, entre literatura e imagem, quer esta se apresente na sua forma estática, como sucede com a pintura ou a ilustração, por exemplo, quer se distinga pelo seu dinamismo, como se observa no caso do cinema. São, na verdade, contruções e reconstruções estéticas dialógicas, intertextuais ou intericónicas que têm vindo a pontuar genericamente a cultura do nosso tempo. Ler o livro e ver o filme, por exemplo, representa um dos percursos possíveis/bastante comuns de convívio simultâneo com duas artes, a literatura e o cinema.

Uma outra forma de (re)aproximação ao texto literário concretiza-se por via da transmutação e/ou expansão ilustração/gráfica de que têm sido algumas obras (ou o conjunto da produção literária de um determinado autor, por exemplo) ostensivamente célebres, tanto do passado, como da contemporaneidade. Os contos clássicos de Beatrix Potter (1866-1943), por exemplo, além de alvo de diversas recriações fílmicas (animação), têm motivado a construção de obras, ou melhor, livros-objecto, nos quais se congregam mecanismos como o 
pop-up, o pull-the-tab, o lift-the-flap, entre outros.. As Aventuras de Alice no País das Maravilhas (1865), clássico universal recriado, como é do conhecimento comum, não apenas por Walt Disney (1951), mas também por Tim Burton (2010), tem inspirado composições ilustrativas muito singulares, como as de Helen Oxenbury ou de Rebecca Dautremer, apenas para citar dois exemplos paradigmáticos. Um outro exemplo ainda: o singular álbum narrativo Onde Vivem os Monstros (1963), de Maurice Sendak ${ }^{1}$, transmutado em película cinematográfica, com realização de Spike Jonze, em 2009, deu também origem, em parte, ao pop-up intitulado Maman? (2009), volume que, com especial cuidado e imaginação, recria o universo diegético e ideotemático algo assombrado/sombrio de Maurice Sendak. E os exemplos multiplicam-se, passando, igualmente, também pelas inúmeras revisitações visuais/gráficas de que têm sido alvo textos de origem tradicional oral, como $O$ Capuchinho Vermelho ou Hansel e Gretel. Aliás, O Capuchinho Vermelho é, a vários títulos, um caso especial de pervivência e de fertilidade inspiradora -chamemos-lhe assimcomo provam as variadíssimas (infinitas?) recriações que originou.

\section{Harry Potter e a Pedra Filosofal: sobre a leitura e a interpretação visual de Jim Kay}

A obra sobre qual centraremos a nossa atenção, Harry Potter e a Pedra Filosofal, um dos mais impressivos fenómenos literários/editoriais do século XX, não foge à tendência que vimos de enunciar e de exemplificar.

Editado em $1997^{2}$, este constitui o título inaugural de uma série que conta com sete livros, um conjunto de obras com mais de 450 milhões de cópias vendidas, traduzida em cerca de 70 idiomas e que inspirou ou foi adaptada em oito filmes pela Warner Brothers ${ }^{3}$. O best-seller-que é também um longseller, na medida em que continua a ser vendido e lido, mesmo após volvidos mais de vinte anos da sua primeira edição ${ }^{4}$ - Harry Potter e a Pedra Filosofal, de J. K. Rowling (do 1965), independentemente das críticas de que tem sido

Obra com ilustrações de Maurice Sendak, cenários de Arthur Yorinks e mecanismos gráficos da autoria de Matthew Reihart, publicada em 2009 por L' École des Loisirs.

2 Lançado no dia 26 de Junho de 1997.

3 Série britânico-americana de 8 filmes que foram dirigidos por Chris Columbus (1 e 2); Alfonso Cuarón (3), Mike Newell (4) e David Yates (5).

4 Em Portugal, por exemplo, em Setembro de 2016, contamos já com a 40ª edição. 
alvo $^{5}$, foi a porta de entrada de um elevado número de leitores -jovens, obviamente, mas também adultos- num universo protagonizado por Harry, os seus amigos e os seus inimigos, um grupo de figuras que passaram a fazer parte da sua realidade psicológica, dominando a sua imaginação.

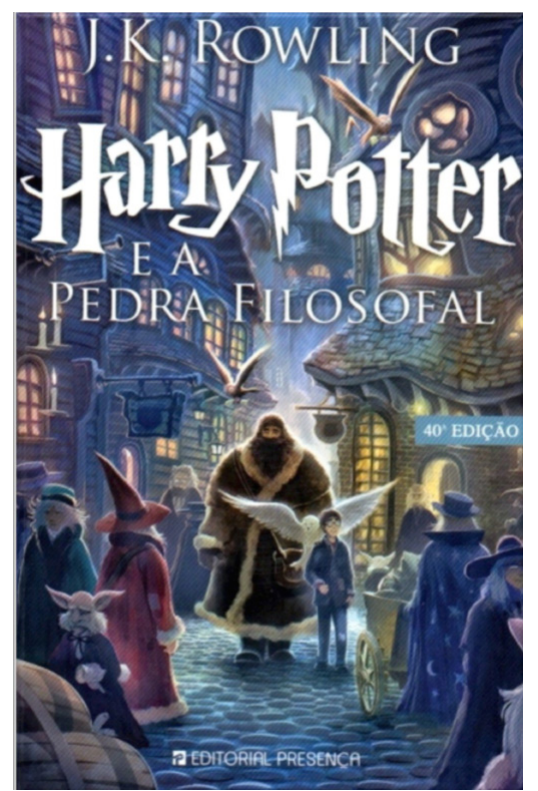

Figura 1. Capa de Harry Potter e a Pedra Filosofal (1997).

Fenómeno editorial global, sem precedentes, os livros de J. K. Rowling, em concreto o primeiro que aqui destacaremos, ostentam uma prosa espirituosa, rica em alusões e dominada por um enredo engenhoso, além de possuírem, como temas unificadores, a perda e a morte, o amor e a magia, como acentua Duncan (2009). E este último aspecto, como preconiza esta investigadora, representa um importante factor de atracção para os leitores. Com efeito, conforme acrescenta a mesma autora,

[...] they trust its veracity, believe in Harry's increasing pain, anger and anxiety, and feel empowered by the way in which he and his loyal friends stand up the forces of evil and terror. It is their own inner resources, tenacity, loyalty and responsability as much as their knowledge of magic that enables them to confront the megalomaniacal nihilism of Voldemort (Duncan, 2009: 194).

5 Por exemplo, o crítico literário Harold Bloom atacou o valor literário de Potter, afirmando que a "Mente de Rowling é tão governada por clichés e metáforas mortas que ela não tem estilo de escrita" (Bloom, 2003). Além disso, Bloom discorda com a noção comum de que Harry Potter foi algo bom para a literatura por encorajar as crianças a ler. 
Além disso, e seguindo a perspectiva de Lurie, "Another attraction of the Potter books is that the good characters are not perfect. [...] Though Rowling's child heroes are imperfect, they are usually smarter and braver than adults" (Lurie, 2004: 117).

Muito provavelmente, pelos motivos brevemente aludidos, em 2015, este volume é cuidadosamente reeditado, com o texto integral, numa edição com uma dimensão/formato considerável, em capa dura, com mais de 100 ilustrações, da autoria do inglês Jim Kay (Derbyshire, 1974), vencedor da Kate Greenway Medal, com a obra A Monster Calls/Sete Minutos depois da Meia-Noite (2011), de Patrick Ness.
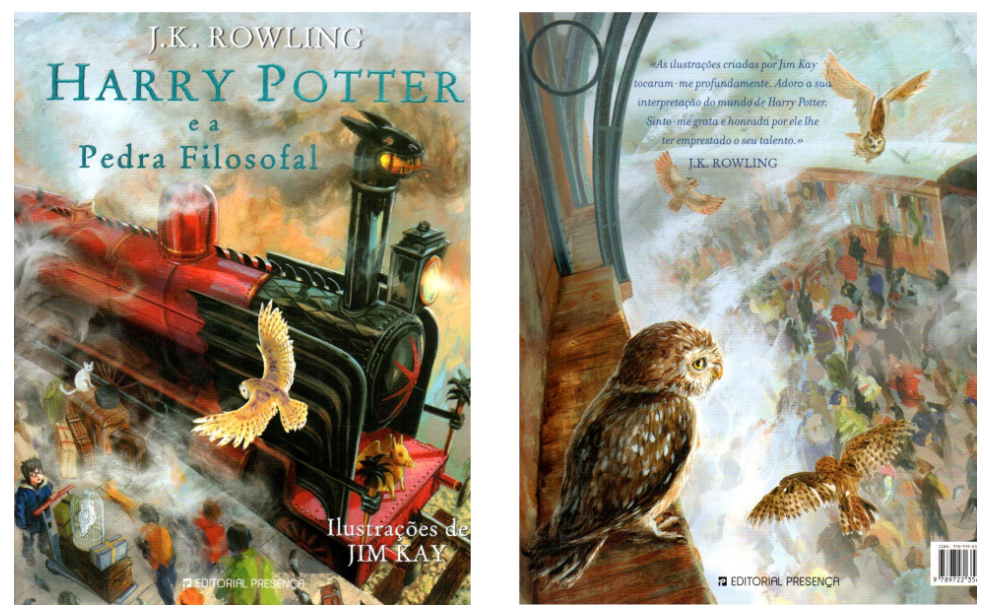

Figuras 2 e 3. Capa e contracapa de Harry Potter e a Pedra Filosofal (2015).

A pedido da própria autora ${ }^{6}$, Jim Kay, não conseguindo esconder a sua insegurança ${ }^{7}$, dedica-se, assim, a essa magistral tarefa que foi a ilustração dos dezassete capítulos que compõem Harry Potter e a Pedra Filosofal ${ }^{\circledR}$. Aliás, as suas requintadas composições visuais não ocupam apenas as páginas de cada um desses capítulos. Estendem-se, na verdade, aos próprios elementos pa-

6 Curiosamente, J. K. Rowling ensaiou várias ilustrações à medida que foi escrevendo as suas narrativas. Ver http://www.artistdaily.com/blogs/drawing/jk-rowling-drawings (consultado no dia 18/10/2017).

7 Afirma Kay: "You don't want to be known as the person who ruins the most popular children's book in history." (Wood, 2015).

8 Em 2016, veio a lume, com ilustrações igualmente da sua autoria, a obra Harry Potter e a Câmara dos Segredos. 
ratextuais do volume. Além da sobrecapa do livro, elemento que constitui uma unidade visual e que retoma uma dupla página do miolo da obra, em concreto do capítulo seis - "A viagem da plataforma nove e três quartos" -, as ilustrações de Kay encontram-se igualmente de x«que criam, a partir, um especial heorizonte de ecpectativas» nas guardas iniciais e nas guardas finais, evidenciando estas uma configuração distinta, embora surjam compostas nos mesmo tons cinza e negro e recriem ambas um espaço físico nocturno, encoberto ou tempestuoso, em certa medida, de contornos góticos. Também a folha de rosto, a ficha técnica, a página das dedicatórias e a dos agradecimentos, assim como o índice ostentam detalhes visuais que desencadeiam, à partida, um especial "horizonte de expectativas".

$\mathrm{Na}$ realidade, mesmo quando as páginas parecem aparentemente não ser ilustradas, observamos a presença de cor e imagem esbatida, em marca de água, surgindo, assim, o texto verbal sobreposto. Efectivamente, se nem todas as páginas se apresentam ilustradas, são, porém, tratadas artisticamente. Com frequência, este tipo de composição artística cria uma atmosfera sugestiva, remetendo para o passado, por exemplo, e fazendo parecer que o texto/o papel é antigo ou se reveste de uma dimensão histórica, aspecto que pode ser observado logo nas páginas duplas nas quais se encontra registado o índice da obra.

Uma particularidade compositiva que merece referência diz respeito ao momento e à forma como as personagens são introduzidas. Em certos casos, a sua apresentação é primeiramente efectuada a partir de um discurso verbal bastante descritivo, pormenorizado, marcado pela adjectivação expressiva e múltipla, pelas sugestões visuais ou pelas comparações, por exemplo. Tomemos como exemplo a caracterização que é feita de Dumbledore, logo no primeiro capítulo:

Nunca fora visto em Privet Drive ninguém que se parecesse com aquele homem. Era alto, magro e muito velho, a julgar pela barba e pelo cabelo prateado, ambos tão longos que lhe chegavam à cintura. Usava uma capa até aos pés, um manto cor de púrpura que varria o solo, e botas afiveladas de tacão. Tinha uns olhos azuis muito claros que brilhavam intensamente por detrás de uns óculos de meia-lua. O nariz era longo e torto como se lho tivessem partido pelo menos duas vezes. O nome desse homem era Albus Dumbledore. (Rowling, 2015: 7).

Esta figura central apenas surge visualmente recriada, num retrato devidamente legendado, já no capítulo seis ("A viagem da plataforma nove e 
três quartos”), em concreto na página 85 , uma representação decorrente da referência a esta personagem num cromo cujo texto é lido por Harry, durante a viagem, no Expresso de Hogwarts.

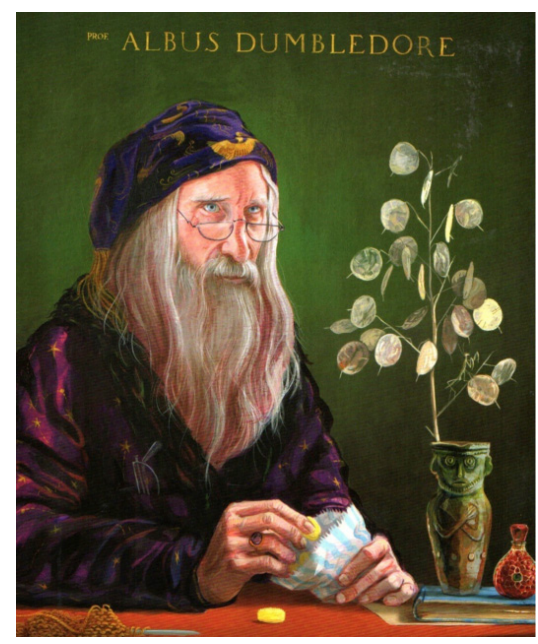

Figura 4. Retrato de Albus Dumbledore.

Em contrapartida, o contacto que o leitor tem com outras figuras concretiza-se de forma inversa, como atesta, por exemplo, o facto de uma ilustração de Hagrid, em meia página, surgir logo no primeiro capítulo (em concreto, na página 10), revelando a sua face e a sua postura a conduzir uma motorizada, e a sua apresentação verbal ocorrer apenas na página seguinte:

Se a moto era grande, o que dizer do homem que vinha lá sentado? Devia ter o dobro da altura de um indivíduo normal e era, pelo menos, cinco vezes mais largo. Parecia maior do que era humanamente possível e verdadeiramente animalesco - os cabelos e a barba negros, ambos emaranhados, ocultavam-lhe a maior parte do rosto, as mãos pareciam tampas de caixotes do lixo e os pés, dentro de umas enormes botas de couro, lembravam dois golfinhos bebés. Nos braços fortes e musculados transportava uma trouxa de cobertores (Rowling, 2015: 11).

O que sobressai, de facto, da representação visual de certas personagens é, além de, em certos casos, uma construção próxima da "fotográfica", com traços realistas, a valorização de algumas das suas vivências ou dos seus momentos mais incertos, vulneráveis ou marcados por uma especial densidade dramática. Desde o quadro visualmente múltiplo que antecede a abertura da narrativa no capítulo um, uma representação dominada pela família Dursley 
e, muito particularmente, pelo seu filho Dudley (que, ainda que ligeiramente cómica, pela boçalidade da criança, reflecte a disfuncionalidade desta família), passando pelas imagens marcadamente dramáticas de Harry dentro do armário, no capítulo dois, e ainda do protagonista e do seu reflexo no espelho, depois de ver os pais (no capítulo doze - página 170), até ao retrato do herói no último capítulo, as representações visuais das figuras da narrativa distinguem-se pela forte carga emotiva que deixam transparecer. Sobre as personagens, ressalta, ainda, a forma expressiva e impressiva como os seus gestos e os seus movimentos, ou seja, a sua configuração actancial ${ }^{9}$, muitas vezes em forma de voo (por exemplo, na página 194), surgem pictoricamente reinventados, a partir de uma técnica que tira partido da sobreposição de traços e de tons, como se pode constatar no capítulo onze, na página 157.
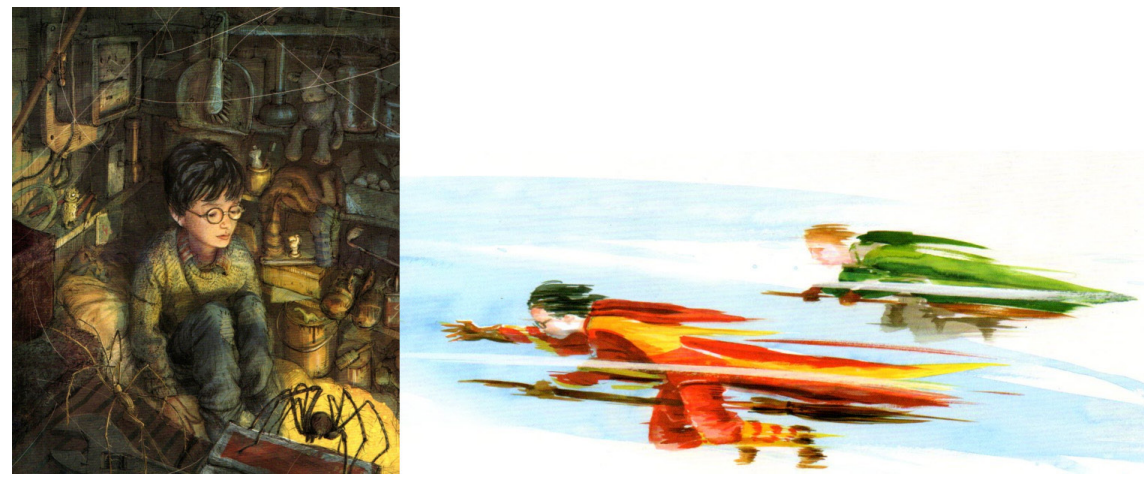

Figuras 5 e 6. Pormenores visuais do miolo da obra.

De igual modo, a recriação visual dos cenários ou dos espaços físicos em que acção tem lugar merece uma reflexão, dadas as especificidades atinentes ao cromatismo, ao modo como é usada a cor para representar o volume ou a luz, à composição, à perspectiva, entre outras. Predominantemente nocturnos, muitos cenários possuem como elemento central um edifício, uma casa (por exemplo, nas páginas 50 e 51) ou um castelo (por exemplo, na página 89), cuja representação reitera, em certa medida, a ideia defendida, por exemplo, por Blake, que considera que Harry Potter explora o passado, o antigo, em vários domínios (Blake, 2009: 308).

9 Curiosamente, em Setembro de 2017, passou a ser comercializada uma versão "animated kindle ebook" da obra: https://ebookfriendly.com/harry-potter-illustrated-jim-kay-kindle-in-motion/. 
Em contraste, as duas representações visuais repletas de pormenores de dois frisos de lojas, patentes no capítulo cinco (páginas 60-63), apresentadas a partir de uma perspectiva frontal, paralela e linear, com alguns pormenores deformados/deformativos, surgem suficientemente iluminadas e representam um verdadeiro desafio à capacidade interpretativa/investigativa/detectivesca do leitor que rapidamente mergulha na observação/leitura de uma pluralidade de elementos icónicos sobrepostos, associados, organizados em conjuntos temáticos

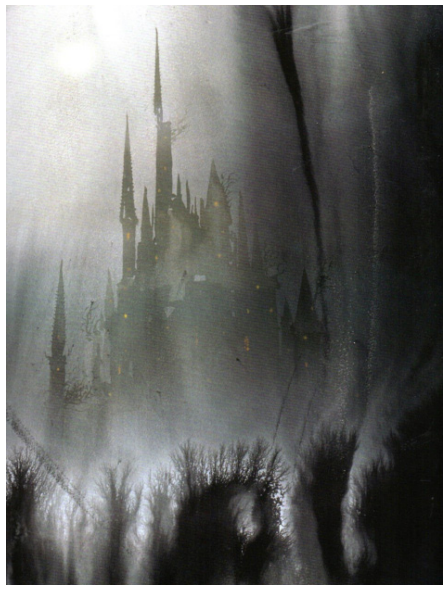

Figura 7. Pormenor visual do miolo da obra. (chapéus-de-chuva, espelhos, telescópios, corujas, etc.). Clara/luminosa é também a dupla página que recria a partida de comboio, o verdadeiro cronotopo, na perspectiva de Pinsent (2005), do protagonista, assim como a imagem, igualmente em dupla página, correspondente à "pequena cabana na orla da floresta proibida" (Potter, 2015: 113) onde vivia Hagrid. Na ilustração da "Floresta Proibida" (capítulo 15), o nocturno, o escuro e o sombrio são cruzados por raios de luz e pela brancura de um unicórnio, um registo visual do qual emerge a magia que perpassa toda a narrativa e ao qual não se encontra alheia uma forte carga simbólica.

Globalmente, uma análise mais atenta permite concluir que a forma como ou o espaço onde Kay incorpora as ilustrações nas páginas da obra não segue um ritmo, uma sequência ou uma estrutura repetitiva ou paralelística, por exemplo. Por outras palavras, nem todas as páginas possuem ilustrações, algumas ilustrações ocupam páginas duplas, outras apenas metade da página, assemelhando-se a um friso (como sucede nas páginas 60-63), detalhes visuais são integrados na própria mancha gráfica do texto verbal, enfim, não existe uma "regra", parecendo que as imagens sustentam, elas próprias, uma linha narrativa. Com efeito, este tipo de estratégia, baseada na diversidade de disposições e de opções compositivas, favorece, em nosso entender, a criação de um quadro imagético muito imaginativo, pessoal/individual, bastante livre, alavancado, sempre, ora por antecipação, sugestão ou catáfora, ora por (uma espécie de) confirmação pelo próprio texto literário. As imagens mentais que o leitor constrói acabam, pois, por correr, quase sempre, paralelamente ao texto. 
Importa, pois, aqui equacionar aquilo que verdadeiramente acarreta, em termos receptivos, a profusão imagética a que nos temos vindo a referir. Quais os efeitos/consequências no processo de leitura e de interpretação da obra ou do texto de Rowling? $\mathrm{Na}$ verdade, antes de tudo, constata-se um efeito prático -chamemos-lhe assim- ou, mais especificamente, no próprio processo de leitura que passa, neste caso, a ter de integrar/contemplar um outro tipo de leitura, a leitura visual ou de imagens. Assim, a leitura torna-se bimédia, dual e mais estendida/

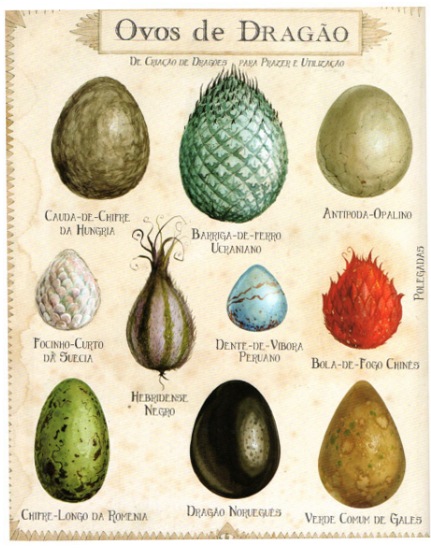

Figura 8. Pormenor do miolo da obra. extensa, requerendo um outro tipo de atenção por parte do destinatário extratextual. Além disso, as ilustrações expandem e acentuam inevitavelmente a capacidade sugestiva do texto verbal, por via, por exemplo, de páginas duplas como as que são dedicadas aos Trolls - "O Guia de Trolls de Newt Scamander” (páginas 146-147) -, ao dragão norueguês (páginas 1901-191), ou, ainda, neste caso, apenas uma página, aos ovos de dragão e às suas especificidades (página 184).

Com efeito, são assíduas as imagens que evidenciam traços próprios da ilustração científica, designadamente pela precisão, pelo rigor, pela acuidade, pelos cuidados pormenores anatómicos, entre outros, com que surge representado o mundo natural/a vida selvagem, em geral. A este título, veja-se, por exemplo: a recriação da coruja patente no centro das páginas 4 e 5 ; das aranhas, na página 17; do lagarto que ornamenta a abertura do capítulo dois, na página 14; ou do gorila, na página 20.

Esse "poder mágico de sugerencias que toda imagen lleva tras de sî" (Sevilla, 1995: 88) é decorrente, no caso da composição visual de Kay, de pormenores visuais cuidadosamente construídos/apresentados, como procurámos explicitar, muitas vezes, em traços que permitem aproximar a sua linguagem artística da estética barroca ${ }^{10}$ (vide, por exemplo, página 99), e colocados, não raras vezes, em espaços da página que, devido à opção gráfica da disposição

10 Genericamente, a estética barroca singulariza-se pelo exagero ou excesso de detalhes e/ou ornamentos, bem como pelos jogos luz-sombra (Carchia e D'Angelo, 2009). 
do texto verbal em duas colunas, se encontram desocupados -por exemplo, entre as duas colunas, como se pode observar logo na abertura do capítulo segundo "O vidro desaparecido" (p. 14) - ou, em outros casos, a partir da integração na própria mancha gráfica correspondente às palavras, como nas páginas 17, 70, 86 e 87, 224 e 225, apenas para citar alguns exemplos.

Uma nota, ainda, para assinalar o facto de tanto na sua primeira edição, com um formato dito convencional, sem ilustrações, ainda que uma capa bastante sugestiva, como nesta nova edição, profusamente ilustrada, Harry Potter e Pedra Filosofal se situar no universo dos "crossover books" ou dos livros que transcendem categorias (Watkins, 2003: 16), sobressaindo como uma narrativa juvenil que é, afinal, para leitores de todas as idades, que tem um públicoalvo duplo ou que oferece simultaneamente algo a jovens e a adultos ${ }^{11}$.

Daí que, na nossa perspectiva, a composição visual de Kay se aproxime desse leitor dual essencialmente por duas vias (Colomer, 2010: 203): a empatia emotiva, uma vez que as suas ilustrações estimulam a afectividade (a simpatia, o medo, etc.), e o desafio intelectual, na medida em que "provoca" o leitor, através de jogos de cumplicidade e de descoberta, da presença de ambiguidades, entre outros, aspectos inerentes, por exemplo, à ilustração presente na página 39, figuração do Guarda das Chaves, personagem dúbia cuja indumentária possui elementos que remetem para o universo dos piratas.

Afigurando-se uma verdadeira obra de arte (diríamos, mesmo, uma composição construída com base em pinturas esteticamente conjugadas), na qual nenhum pormenor parece ter sido deixado ao acaso, uma construção visual densa, requintada e/ou refinada, como atestam as ilustrações patentes nas páginas 170, uma imagem dramática de Harry junto ao espelho, e da página 110, na qual se recria a figura sinistra do Professor das Poções, respectivamente, Harry Potter e a Pedra Filosofal, ilustrado por Jim Kay, é também, em última instância, a materialização de uma leitura pessoal, individual, concretizada, com a subjectividade que lhe é inerente - por se tratar da leitura de um texto literário -, encetada por um artista, um ilustrador, sensível, atento e culto leitor, um leitor que interpreta a obra de J. K. Rowling muito depois da

11 "A plain-cover edition has also appeared in England, for adults who are embarrassed to be seen reading a children's book. Though this edition costs two pounds more than the original, it very soon sold twenty thousand copies" (Lurie, 2004: 122). 
data da sua primeira edição, ora representando visualmente de forma próxima as suas palavras, ora inspirando-se apenas nelas.

Ainda que pretendendo apenas uma análise sucinta, importa, no contexto desta releitura, considerar Harry Potter. A Pop-Up Book (2010), volume desencadeado pelo filme, e assinado por Lucy Kee, com arte de Andrew Williamson e engenharia do papel de Bruce Foster.
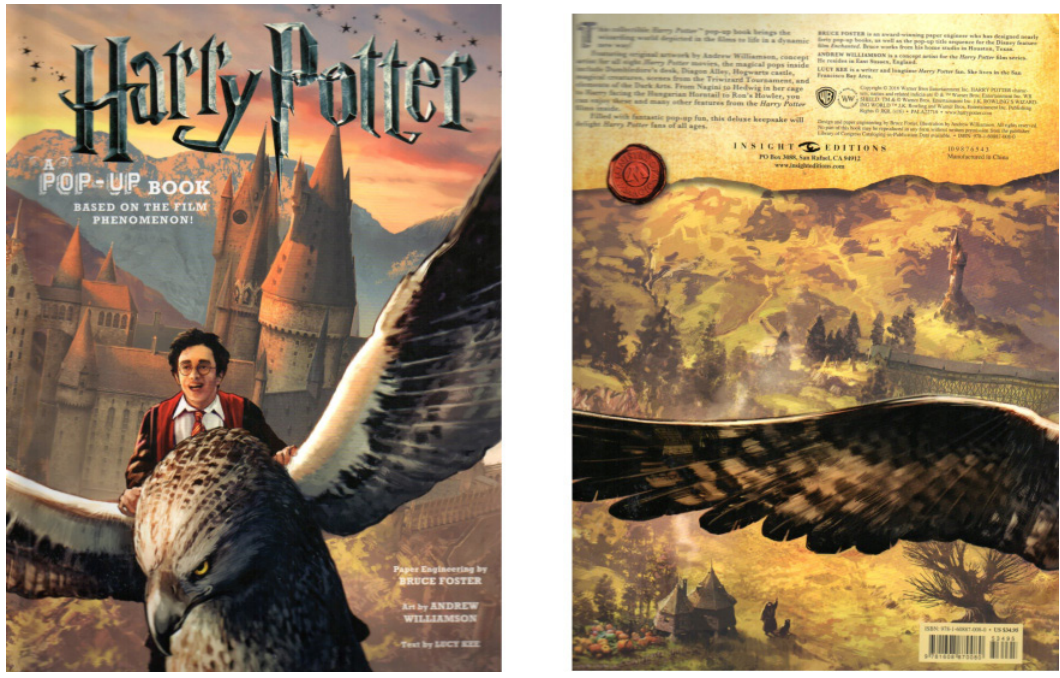

Figuras 9 e 10. Capa e contracapa de Harry Potter A Pop-up Book.

Baseado no fenómeno cinematográfico ou nos oito filmes originados pelas obras de Rowling, este é um livro que se distingue pela sofistificação dos recursos gráficos e visuais que mobiliza, designadamente e com notória assiduidade o pop-up, conforme se anuncia na capa da obra. Em seis páginas duplas, cinco das quais dominadas por um pop-up de dimensão considerável, a obra evidencia uma configuração bastante impressiva, causando um forte impacto visual. São múltiplos e em elevado número os elementos textuais que compõem a obra, registados ou escondidos em espaços variados, por exemplo, dentro de envelopes, e que se associam a/integram, em certos casos, uma rica linguagem visual, através da qual se procura mimetizar uma ambiência antiga ou histórica, temporalmente longínqua e, de certo modo, espacialmente exótica. A arquitectura da obra assenta em quadros temáticos - a saber, "Dumbledore's office", "Diagon Valley", "Hogwarts School of Witchcraft and Wizardry", etc. -, apresentando uma legenda que possibilita uma leitura esclarecida dos elementos icónicos que os pop-up recriam. 


\section{Considerações finais}

Concluímos, lembrando que sobre a série Harry Potter têm sido pronunciadas variadíssimas críticas, tanto de âmbito divulgativo (por exemplo, pelos media), como académico: repleto de lugares-comuns e de esterótipos, esteticamente discutível ou responsável pela homogeneização dos jovens leitores e pela promoção de uma visão patriarcal e convencional do mundo (Zipes, 2001), entre outras. Harry Potter e a Pedra Filosofal pode parecer assim aos olhos críticos de muitos estudiosos/investigadores ou de alguns leitores comuns. Aos de outros poderá ser entendido como um "must-read for anyone of any age" (King, 2009: 662). Existe, porém, um facto que, no nosso entender, parece mais ou menos indiscutível: a sua plasticidade discursiva e o seu enredo, repleto de sombras, de claros-escuros, de mistérios ou de enigmas, enfim, de "espaços em branco" que pontuam a narrativa e que possibilitam leituras múltiplas. E foi essa pluralidade semântica ou essa plurissignificação que deu azo às reinvenções/releituras visuais que aqui revisitámos e que, prevemos, sustentará a sua pervivência ao longo de gerações sucessivas de leitores.

Sara Reis da Silva

CIEC-IE-Universidade do Minho

\section{Bibliografia}

Blake, Andrew. 2009. "Harry Potter and the reinvention of the past", em Children's Literature. Classic texts and contenporary trends (eds. Heather Montegomery e Nicola J. Watson). New York: Palgrave Macmillan-The Open University, pp. 303310 .

Bloom, Harold. 2003. "Dumbing down American readers" em Boston.com, http://archive.boston.com/news/globe/editorial_opinion/oped/articles/2003/09/24/ dumbing_down_american_readers/ [Consulta: 16/10/2017].

Carchia, Gianni e D’Angelo Paolo (dir.). 2009. "Barroco", em Dicionário de Estética. Lisboa: Edições 70, pp. 49-51.

Colomer, Teresa. 2010. Introducción a la literatura infantil y juvenil actual. Madrid: Editorial Síntesis (2a ed. ampliada).

Duncan, Diane. 2009. Teaching Children's Literature. Routledge: London/New York. 
Even-Zohar, Itamar. 1997. "Factors and dependencies in culture: a revised outline for polysystem culture research", em Canadian review of comparative literature, $\mathrm{v}$. XXIV, $n^{\circ} 1$, pp. 15-34.

Ewers, Hans-Heino. 2009. Fundamental concepts of children's literature research. NY/ London: Routledge.

Nikolajeva, Maria. 2005. Aesthetics approaches to children's literature. London/ Maryland/Toronto/Oxford: The Scarecrow Press.

Nikolajeva, Maria e Scott, Carole. 2011. Livro ilustrado: palavras e imagens. São Paulo: Cosac Naify (trad.: Cid Knipel).

Nodelman, Perry. 1988. Words about pictures. Athens/Georgia: University of Georgia Press.

Kee, Lucy. 2010. Harry Potter A Pop-up book based on the film phenomenon. USA: Insight Editions (arte: Andrew Williamson; engenharia do papel: Bruce Foster).

King, Carol. 2009. "Harry Potter and the Philosopher's Stone", em 1001 Cildren's Books you must read before you grow up (ed. Julia Eccleshare). London: Quintessence, p. 662.

Lurie, Alison. 2004. "The perils of Harry Potter", em Girls and Boys Forever. London: Vintage, pp. 113-123.

Pinset, Pat. 2005. "Theories of genre and gender: change and continuity in the school story", em Modern Children's Literature (eds. Catherine Butler e Kimberley Reynolds). New York: Palgrave, pp. 105-120.

Rowling, J. K. 2016. Harry Potter e a Pedra Filosofal. Queluz de Baixo: Editorial Presença ( $40^{\mathrm{a}}$ ed.).

Rowling, J. K. 2015. Harry Potter e a Pedra Filosofal. Queluz de Baixo: Editorial Presença (ilustrações de Jim Kay).

Sevilla, Julio Porras. 1995. "La defensa de la imagen", em El niño, la literatura y la cultura de la imagen (coords. Pedro C. Cerrillo e Jaime García Padrino). Cuenca: Ediciones de la Universidad de Castilla-La Mancha, pp. 87-89.

Watkins, Tony. 2003. "Topographie de la librairie magique: la littérature pour la jeunesse récente en Grande-Bretagne", em Perspectives contemporaines du roman pour la jeunesse (dir. Virginie Douglas). Paris: L' Harmattan, pp. 13-35. 
Wood, Gaby. 3 outubro 2015. "Jim Kay: 'I worried I'd ruin the most popular children's book in history", em The Telegraph, http://www.telegraph.co.uk/ books/what-to-read/harry-potter-illustrated-jim-kay/ [Consulta 16/10/2017].

Zipes, Jack. 2001. "The Phenomenon of Harry Potter, or Why All the Talk?”, em Sticks and stones. The Troublesome success of children's literature from Slovenly Peter to Harry Potter. Routledge: New York/London, pp. 170-189. 